\title{
JULGAMENTO DE CRIMES INTERNACIONAIS EM ÂMBITO NACIONAL E INTERNACIONAL: ENTRE JUSTIÇA E REALPOLITIK
}

Kai Ambos

\section{INTRODUÇÃO}

O TPI na Haia (doravante "TPI" ou Tribunal) é o primeiro tribunal penal internacional permanente na história da humanidade baseado em um tratado internacional. Foi estabelecido no dia 17 de julho de 1998 por mais de 120 países, adotando-se o "Estatuto de Roma do TPI" (doravante "Estatuto" ou "Estatuto do TPI"), na Conferência Diplomática de Plenipotenciários das Nações Unidas para a instauração de um TPI. Atualmente (20 de outubro de 2006), 102 países ratificaram o Estatuto e 139 subscreveram-no ${ }^{1}$. O Estatuto entrou em vigor em 1 de julho de 2002. Até 10 de fevereiro de 20061732 comunicados foram recebidos vindos de cidadãos e grupos de 103 diferentes Estados, denunciando crimes cometidos em 139 Estados. ${ }^{2}$ Somente em três situações ou casos foram abertas investigações formais, conforme o artigo 53 do Estatuto ${ }^{3}$. Destas, duas foram remetidas ao promotor com base nos artigos 13(1)(a) e 14 do Estatuto (Uganda e República Democrática do Congo) e outra

\footnotetext{
* Traduzido por: Cássio Eduardo Zen, José Carlos Portella Jr e Larissa Pereira Rodrigues, sob a supervisão e revisão da Prof. Dra. Tatyana Scheila Friedrich. Texto final em português revisto e atualizado pelo Autor.

** Titular de Direito Penal, Processual Penal, Comparado e Direito Penal Internacional da Universidade de Göttingen (Alemanha), chefe do departamento de direito penal estrangeiro e internacional e juiz no tribunal Estatal de Landgericht Göttingen.

1 Para uma lista atualizada de subscrições e ratificações, consultar a página oficial do TPI http://www.icc-cpi.int/asp/statesparties.html , ver também http://www.iccnow.org/countryinfo/worldsigsandratifications.html e http://web.amnesty.org/pages/icc-signatures_ratifications-eng. Sobre 0 histórico evento da $100^{\underline{a}}$ subscrição, ver as declarações em http://www.iccnow.org/100th/index.html.

${ }_{2}$ Ver no Gabinete do Promotor a lista atualizada de comunicações, http://www.icccpi.int/organs/otp/otp_com.html. Conforme o relatório de atividades do Tribunal, de 16 de setembro de 2005, ICC-ASP 4/16, Assembléia dos Estados Parte, quarta sessão, página 7, http://www.icc-cpi.int/library/asp/ICC-ASP-4-16_English.pdf, até o encerramento desta, 1497 comunicações foram submetidas.

${ }^{3}$ Para esta e para a informação seguinte, ver SUPRA, nota 2.
}

Revista Brasileira de Direito Internacional, Curitiba, v.1, n.1, jan./jun.2005 
pelo Conselho de Segurança, com base no artigo 13(1)(b) (Darfur, Sudão) ${ }^{4}$. Uma quarta situação, referida pela República Centro Africana permanece sob análise, assim como uma situação levada ao Tribunal por uma declaração de aceitação de jurisdição por um Estado não membro (Costa do Marfim), conforme o artigo 12(c) Estatuto do TPI. Desta maneira, nenhuma das três investigações em andamento é uma investigação motu proprio, em outras palavras, em nenhuma dessas investigações o promotor atuou ex officio, com base nas faculdades que os Estados Partes Ihes concederam através do artigo 15, confiando nas informações submetidas através das comunicações, pelas vítimas dos delitos (canalizados pela ONU ou outras organizações, ver artigos 13(1)(c) e 15 do Estatuto do TPI). Mais adiante voltaremos a tratar deste tema.

\footnotetext{
${ }^{4}$ Resolução 1593 (2005) do Conselho de Segurança, adotada por 11 votos a favor e 4 abstenções (Argélia, Brasil, China e Estados Unidos), ver em http://www.un.org/News/Press/docs/2005/sc8351.doc.htm
}

Revista Brasileira de Direito Internacional, Curitiba, v.1, n.1, jan./jun.2005 


\section{INICIANDO UMA INVESTIGAÇÃO MOTU PROPRIO}

Diante do exposto, passamos à análise da posição do Promotor no sistema do TPI. Desde o início das negociações para o TPI, os Estados desejavam um Promotor independente e forte, comparável com o Promotor dos sistemas nacionais de justiça penal, quem - é claro! - tem a faculdade de iniciar investigações ex officio ${ }^{5}$. Obviamente, havia forte oposição contra essa faculdade motu proprio do Promotor por países influentes, sobretudo pelos Estados Unidos da América, mas também pela China e Índia. Naquele período (1998) a Administração Clinton era investigada pelo Conselheiro Kenneth Starr no caso Lewinsky e estava, portanto, altamente sensível com qualquer Promotor independente que, quase como uma bomba-relógio ativa, poderia a qualquer tempo explodir e enlouquecer. Sob a luz desta controvérsia nas negociações em Roma, o melhor compromisso que se pôde alcançar foi prover um controle judiciário das investigações do Promotor e essa foi a origem da Câmara de Questões Preliminares, ou "Pre-Trial Chamber" (moldada segundo a Câmera de Acusação Francesa "Chambre d'Accusation" e o Grande Júri dos Estados Unidos). Essa câmara atua numa fase bastante prematura, na hipótese de uma investigação motu proprio, especialmente quando o Promotor conclui que "há embasamento suficiente para seguir à investigação (...)" (Artigo 15(3) do Estatuto do TPI). Tal intervenção ocorre em momento muito anterior se comparado a procedimentos nacionais similares, como o alemão "Zwischenverfahren". Apesar disso abrir espaço a críticas, a alternativa de um controle político do Promotor, por exemplo, pelo Conselho de Segurança (e desta maneira pelos Estados Unidos) era um cenário muito pior. No final das contas, o Conselho de Segurança adquiriu faculdade de iniciar uma investigação (artigo 13(b)) e o direito de suspender uma investigação ou processo por 12 meses renováveis (artigo 16). Seja como for, enquanto o momento das negociações pode explicar as restrições impostas ao Promotor

\footnotetext{
${ }^{5}$ Ver A Declaração de Fraiburgo Sobre a Posição do Promotor de um Tribunal Penal Internacional. ARBOUR, L.; ESER, A.; AMBOS, K.; SANDERS, A (editores). The Prosecutor of a Permanent ICC. Freiburg im Breisgau: Instituto Max Plankt. 2000. p.667 e seguintes. Impresso em inglês, francês, espanhol e alemão.
}

Revista Brasileira de Direito Internacional, Curitiba, v.1, n.1, jan./jun.2005 
durante a fase pré-judicial, não explica o porquê do Promotor não ter invocado sua faculdade explícita motu proprio até hoje.

Como mencionado no início deste trabalho, apesar do monumental número de comunicações enviadas ao TPI, nenhuma delas acarretou numa investigação formal conforme 0 artigo 53 do Estatuto. De acordo com informação recente do Gabinete do Promotor $^{6}$, 80\% destas comunicações estavam claramente fora da jurisdição do Tribunal: em 5\% das comunicações não havia jurisdição temporal (Artigo 11 do Estatuto do TPI) ${ }^{7}$ visto que as comunicações se referiam a eventos anteriores a entrada em vigor do Estatuto, no dia $1^{\circ}$ de julho de $2002 ; 24 \%$ dos fatos alegados não estavam no âmbito de aplicação da competência material, ou seja, não faziam referência à genocídio, crimes de lesa-humanidade ou crimes de guerra ${ }^{8}$ (artigos 5-8 do Estatuto do TPI), $13 \%$ se referiam a supostos crimes fora da competência pessoal ou territorial (Artigo 12 do Estatuto do TPI) ${ }^{9}$; por último mas não menos importante, $38 \%$ das comunicações estavam manifestamente infundadas, por exemplo, incluíam demandas de conspiração geral sem detalhes específicos ou concernentes a políticas locais ou nacionais.

Os 20\% restantes das comunicações (por assim dizer, 346 comunicações em números absolutos), as quais conforme o Gabinete do Promotor seriam analisadas posteriormente, foram agrupadas por situações. Apesar disto, o Gabinete do Promotor não informou quantas situações foram

\footnotetext{
${ }^{6}$ Ver Supra, nota 2. Para o manejo das referências e comunicações em geral, ver o Gabinete do Promotor Paper on some policy issues before the Office of the Prosecutor. Referências e Comunicações, http://www.icc-cpi.int/library/organs/otp/policy_annex_final_210404.pdf.

${ }^{7}$ Conforme o artigo 11 do Estatuto, o "Tribunal só terá competência relativamente aos crimes cometidos após a entrada em vigor do presente Estatuto", ou seja, após o 1ํ de julho de 2002. Também terá competência se um Estado ratificou o Estatuto após o encerramento das subscrições. Neste caso, para este Estado, o Estatuto entra em vigor "no primeiro dia do mês seguinte ao termo de um período de 60 dias após a data do depósito do respectivo instrumento de ratificação, de aceitação, de aprovação ou de adesão" (artigos 11(2) e 126(2) do Estatuto).

${ }^{8}$ Conforme 0 artigo 5 do Estatuto, o Tribunal possui competência quanto os crimes de genocídio,crimes de lesa-humanidade, crimes de guerra e o crime de agressão (este último, todavia, é objeto de discussão para se encontrar uma definição acordada, parágrafo 2). Desta maneira, os crimes "ordinários", como homicídio, roubo ou estupro estão fora da competência material do Tribunal. Sobre os crimes, ver AMBOS, Kai. Internationales Strafrecht. München: Beck. 2006. §7, notas marginais (nm.); AMBOS, Kai. in International Criminal Law Quo vadis? Nouvelles Études Pénales. Toulous: AIDP. 2004. p.219-282; AMBOS, Kai. Los crímenes más graves en el derecho penal internacional. Ciudad de Mexico: Instituto Nacional de Ciencias Penales. 2005.

${ }^{9}$ Artigo 12 limita a competência formal do TPI ao território dos Estados Parte (alínea (a)) ou ao Estado de que seja nacional o suspeito do crime (alínea (b)).
}

Revista Brasileira de Direito Internacional, Curitiba, v.1, n.1, jan./jun.2005 
identificadas no total. O título "Análise de Situação", se refere a 23 situações no total, incluindo aquelas que surgiram de comunicações, as três referidas por Estados (Uganda, R.D. Congo, República Centro Africana), aquela referida pelo Conselho de Segurança (Darfur, Sudão) e a declaração ad hoc por um Estado não membro (Costa do Marfim), todas mencionadas acima ${ }^{10}$. Dessa maneira, parece que o Gabinete do Promotor reduziu as 346 comunicações restantes a 18 situações (23 menos 5). De um total de 23 situações (18 comunicações baseadas no artigo 15) seis foram rejeitadas, sete permanecem como "relatório básico" e dez se encontram em "intensa análise"11. Destas dez situações, três conduziram à etapa de investigação (República Democrática do Congo, Uganda e Sudão, como mencionado anteriormente), duas foram rejeitadas (Iraque e Venezuela) ${ }^{12}$ e cinco permanecem sob análise. O Gabinete do Promotor não menciona quais seriam estas cinco, mas é possível inferir das demais situações pendentes que República Centro Africana e Costa do Marfim seguramente Ihes pertencem. Das três restantes, seguramente uma - por conhecimento deste autor - se refere à Colômbia, as outras ao Afeganistão, Burundi, Iraque ou Nigéria ${ }^{13}$. No que diz respeito à relação entre as situações que se originaram de comunicações e que, portanto, estariam legalmente baseadas na faculdade moto proprio do Promotor e às baseadas em outros mecanismos de ação previstos no Estatuto do TPI (referência pelo Estado ou Conselho de Segurança ou declaração de aceitação da jurisdição) cinco destas dez situações tiveram origem nas comunicações, duas entre estas foram rejeitadas e três permaneceram em análise. Em outras palavras, mesmo que algumas comunicações (as quais estão agrupadas nessas três situações) tenham atingido o estágio de análise intensiva, nenhuma atingiu a etapa de investigação conforme o artigo 53 do Estatuto do TPI.

A pouca relevância dada pelo Tribunal ao grande número de comunicações merece atenção especial e ocasiona várias perguntas legais e

\footnotetext{
${ }^{10}$ Ver Supra nota 4 e texto.

${ }^{11} \mathrm{O}$ Gabinete do Promotor (Supra nota 2; texto com notas de rodapé 5 e 7) distingue "relatório básico"("fase II-A") e "análise mais detalhada e intensa"("fase II-B e fase III").

${ }_{12}^{12}$ Ver as decisões publicadas como anexo do Gabinete do Promotor (Supra nota 2).

${ }^{13}$ Estas foram as situações que estavam na fase II (Supra nota 11) em setembro de 2005 (Entrevista com Xabier Aguirre, principal analista de casos do TPI - Gabinete do Procurador (A Haia, 30 de setembro de 2005)).
}

Revista Brasileira de Direito Internacional, Curitiba, v.1, n.1, jan./jun.2005 
factuais, mas cuja análise, no entanto, iria além do alcance deste trabalho. É claro que deve ser solicitado algum controle ou intervenção judicial pela Câmara de Questões Preliminares, em nome das vítimas que não veêm seus interesses sendo suficientemente considerados pelo Gabinete do Promotor. No entanto, é difícil entender como nenhuma comunicação (como parte de uma situação) gere uma investigação (formal), o que certamente melhoraria, em sua totalidade, a imagem do Gabinete do Promotor e do Tribunal, caso algum dia isso acontecesse.

Tomando, como exemplo, o caso da Colômbia onde nas décadas de conflito entre insurgentes, Forças Armadas Oficiais e paramilitares, milhares de civis foram assassinados, torturados, desaparecidos, etc ${ }^{14}$. Apesar de a Colômbia ter ratificado o Estatuto apenas em 5 de agosto de 2002, tornando-se efetivo em $1^{\circ}$ de novembro de 2002 (Artigo 126(2)) e, além disso, o Governo ter invocado o artigo 124 para excluir da jurisdição do Tribunal os crimes de guerra por sete anos (ou seja, até $1^{\circ}$ de outubro de 2009), não seria difícil encontrar crimes contra a humanidade cometidos em território colombiano por nacionais colombianos. Em outras palavras, se o Promotor Chefe, o argentino Luis Moreno Ocampo, estivesse disposto a investigar a situação colombiana motu proprio, certamente poderia fazê-lo. Então porque assim não o fez até hoje? A resposta para essa pergunta está ligada à "realpolitik" e nos remete a um dos temas principais de nosso pequeno estudo.

\footnotetext{
${ }^{14}$ Ver o mais recente, HUMAN RIGHTS WATCH, Human Rights Watch World Report 2006, Events of 2005, Colombia, p.179-186. http:// www.hrw.org/wr2k6/wr2006.pdf
}

Revista Brasileira de Direito Internacional, Curitiba, v.1, n.1, jan./jun.2005 


\section{COOPERAÇÃO DOS ESTADOS NA ETAPA DE INVESTIGAÇÃO}

Provavelmente a expressão mais evidente da dependência do TPI, em particular, e de Tribunais Penais Internacionais, em geral da "Realpolitik", encontra-se na área de cooperação ou não cooperação dos Estados com esses Tribunais. Permitam-nos fazer primeiro algumas observações gerais sobre a cooperação entre Estados vis a vis a cooperação de Estados com os Tribunais Penais Internacionais antes de adentrar em alguns temas técnicos.

\subsection{APLICAÇÃO DO DIREITO PENAL INTERNACIONAL, COOPERAÇÃO VERTICAL E OBRIGAÇÃO DE COOPERAR}

O Direito Penal Internacional pode se fazer cumprir diretamente (modelo direto de aplicação) pelas Cortes Penais Internacionais ou indiretamente (modelo indireto de aplicação) pelas Cortes Nacionais ${ }^{15}$. Pode-se falar somente de aplicação direta do Direito Penal Internacional em um sentido genuíno se os Tribunais Internacionais em questão tiverem poderes supranacionais para fazer cumprir seus próprios atos e decisões, tais como prender criminosos ou realizar investigações em território soberano. Esse é o caso somente de tribunais estabelecidos por ocupação, como Nuremberg e Tóquio, assim como o tribunal especial no Iraque; entretanto, os poderes desses tribunais se encontram limitados ao território ocupado ${ }^{16}$.

Como regra geral, os tribunais internacionais dependem da cooperação dos Estados, não somente para avançar na investigação de crimes internacionais, mas também para a execução de eventuais sentenças ${ }^{17}$. Os Tribunais Internacionais são assim, copiando a famosa frase do processualista alemão Eduard Kern acerca do sistema judicial penal internacional, "como uma

\footnotetext{
15 G. WERLE, Völkerstrafrecht (2003), nm. 195 e ss.; M. C. Bassiouni, Introduction to international criminal law (2003), pp. 18 e ss. e 333 e ss.

${ }^{16}$ Cf. A. CIAMPI, en: A. CASSESE y P. GAETA e J. R. JONES (eds.), The Rome Statute of the ICC, A commentary (2000), Vol. 2, pp. 1711 e ss.

${ }^{17} \mathrm{C}$. KREß et al., en: O. TRIFFTERER (ed.), Commentary on the Rome Statute of the International Criminal Court (1999), Parte 9, nm. 1 e ss.; A. Ciampi (supra nota 16), pp. 1607 e ss.; B. SWART en: A. CASSESE y P. GAETA e J. R. JONES (eds.) (supra nota 16), pp. 1589 e ss.
}

Revista Brasileira de Direito Internacional, Curitiba, v.1, n.1, jan./jun.2005 
cabeça sem braços" ${ }^{18}$. A partir dessa perspectiva, existe, no sentido genuíno acima mencionado, uma implementação indireta da legislação penal internacional por parte dos tribunais internacionais; eles dependem, em outras palavras, de um "modelo indireto de aplicação" para funcionar corretamente ${ }^{19}$.

É evidente que deve haver também regras e princípios de cooperação entre os tribunais internacionais e os Estados. Em princípio, as mesmas regras que regem a cooperação tradicional entre Estados (extradição, assistência legal e ajuda na execução de sentenças) se aplicam em relação aos Tribunais Internacionais. Entretanto, existem maiores diferenças com respeito à terminologia, requisitos prévios e a procedimentos da cooperação. Quando se trata de regras de cooperação vale a pena precisar que o termo correto é "cooperação vertical" para a relação entre Tribunais supranacionais por um lado e organismos internacionais e Estados por outro ${ }^{20}$. Essa cooperação vertical se diferencia da cooperação horizontal entre os Estados soberanos iguais $^{21}$ no fato de que na última não existe obrigação internacional geral de cooperar, mas a cooperação depende da decisão soberana e voluntária do Estado em questão ${ }^{22}$. A cooperação de um Estado com outro exige muitas condições prévias, as quais devem ser satisfeitas conforme o princípio de reciprocidade e a consideração de outros obstáculos que comprometem sua

\footnotetext{
${ }^{18}$ E. KERN, Gerichtsverfassungsrecht (1965), p. 227 com respeito à relação entre o promotor e a polícia.

${ }^{19}$ Cf. M. C. BASSIOUNI (supra nota 15), pp. 18 e ss., y 388 e ss.

${ }^{20}$ Prosecutor v. Blaskic, App. Judgement of October 29, 1997 (IT-95-14-AR108bis.), parágrafo 47 e 54. Mais detalhes a respeito da cooperação vertical em G. SLUITER, International criminal adjudication and the collection of evidence (2002), pp. 82 e ss.; G. SLUITER, en: H. FISCHER e C. KREß y S. R. LÜDER (eds.), The Rules of Procedure and Evidence on Cooperation and Enforcement (2001), pp. 688 e ss.; B. SWART (supra nota 17), pp. 1592 e ss.; J. MEIBNER, Die Zusammenarbeit mit dem Internationalen Strafgerichtshof nach dem Römischen Statut (2003), pp. 10 e ss. Acerca da cooperação com organizações intergovernamentais ver o artigo 87 (6) do Estatuto.

${ }^{21}$ Cf. B. SWART (supra nota 17), pp. 1590 e ss.; G. SLUITER 2002 (supra nota 20), pp. 81 e ss.; K. AMBOS, Finnish Yearbook of International Law 1998, pp. 413 e ss.; W. SCHOMBURG e O. LAGODNY, Internationale Rechtshilfe in Strafsachen, $3^{\text {rd }}$ edn. (1998), introduction nm. 4546; J. A. VERVAELE e A. KLIP, European cooperation between Tax, Customs and Judicial Authorities (2002), pp. 35 e ss.; C. KREß en: H. GRÜTZNER e P.-G. PÖTZ (eds.), Internationaler Rechtshilfeverkehr in Strafsachen, 63. Ergänzungslieferung (2004), comentários preliminares al III 26, nm. 205 e ss.; C. KREB et al. (supra nota 17), parte 9 nm. 3; P. WILKITZKI, International Criminal Law Review 2002, p. 198; J. MEIBNER (supra nota 20), pp. 10 e ss. y 275 e ss.

${ }^{22}$ K. F. NAGEL, Beweisaufnahme im Ausland (1988), p. 72; H. GRÜTZNER, em: M. C.

BASSIOUNI e V. NANDA (eds.), A Treatise on International Criminal Law (1973), pp. 234 e ss.; B. SWART (supra nota 17), pp. 1590 e ss.
}

Revista Brasileira de Direito Internacional, Curitiba, v.1, n.1, jan./jun.2005 
eficácia ${ }^{23}$. A meta de um eficiente sistema de cooperação horizontal (regional) deve ser a redução desses obstáculos.

Em um regime de cooperação vertical, a cooperação, na teoria, não deve depender da decisão soberana dos países envolvidos, tendo em vista que eles se vêem, como regra geral, obrigados a cooperar. Assim, os tribunais ad hoc estabelecidos pelo Conselho de Segurança da ONU podem dirigir petições e ordens aos Estados-membros da ONU. Sua obrigação de cooperar resulta diretamente do efeito vinculante das resoluções do Conselho de Segurança (Artigo 25 da Carta da ONU) que estabeleceram os Estatutos dos Tribunais Ad Hoc e como tal uma obrigação de cooperar (ver, por ex., artigo 29 do Estatuto do Tribunal Penal Internacional para a ex-lugoslávia e no artigo 28 do Estatuto do Tribunal Penal Internacional para Ruanda) ${ }^{24}$. Esses Estatutos, por si mesmos, não contemplam nenhuma reserva para aquele que se nega a cooperar $^{25}$; de igual forma, as regras nacionais e as obrigações convencionais internacionais que se opõem aos Estatutos, não podem, em princípio, ser invocados como argumentos para a negação da cooperação. No caso de descumprimento do dever de cooperar, o Conselho de Segurança da ONU pode impor sanções ao país que cometa a violação ${ }^{26}$.

Durante as negociações do Estatuto do TPI, os países que adotaram uma posição crítica em relação ao Tribunal, advogaram por um regime de cooperação baseado nas regras horizontais tradicionais da ajuda mútua, enquanto os países favoráveis ao Tribunal ("like minded countries") propuseram uma nova forma de cooperação sui generis que leve em conta a

\footnotetext{
${ }^{23}$ Cf. B. SWART (supra nota 17), pp. 1590 e ss.; M. C. BASSIOUNI (supra nota 15), pp. 333 e ss.; G. SLUITER 2002 (supra nota 20), pp. 81 e ss.; J. MEKBNER (supra nota 20), pp. 12 e ss.

${ }^{24}$ Cf. A.-L. CHAUMETTE, International Criminal Law Review 2004, pp. 357 e ss. Os acordos bilaterais sobre cooperação, como os que existem entre Estados Unidos e o Tribunal Penal Internacional para a ex-lugoslávia e o Tribunal Penal Internacional para Ruanda são, portanto, supérfluos desde que os Estados-membros da ONU estabeleceram os requisitos de cooperação em suas leis domésticas (cf. G. SLUITER 2002, (supra nota 20), pp. 63 e ss.; J. GODINHO, Journal of International Criminal Justice 2003, pp. 502 e ss.; para uma visão contrária ver R. KUSHEN, Journal of International Criminal Justice 2003, pp. 517 e ss.).

${ }^{25}$ Cf. Prosecutor v. Blaskic (supra nota 20), parágrafos 26, 47, 54 e 63; ver também os artigos 25 e 103 da Carta da ONU. C. KREB (supra nota 21), III 27, nm. 57; B. SWART (supra nota 17), pp. 1592 e ss.; A. CIAMPI (supra nota 16), pp. 1610-11; A. CASSESE, International criminal law (2003), pp. 357 e ss.; G. SLUITER 2002 (supra nota 20), pp. 47 e ss. y 139 e ss.

${ }^{26}$ Prosecutor v. Blaskic (supra nota 20), parágrafos 26-31,33-37 e regras 7-11, 59 (b) e 61 (e) do Tribunal Penal Internacional para a ex-lugoslávia/Tribunal Penal Internacional para Ruanda.
}

Revista Brasileira de Direito Internacional, Curitiba, v.1, n.1, jan./jun.2005 
posição particular do $\mathrm{TPI}^{27}$. Como resultado, o Estatuto do TPI agora contém um regime misto de cooperação que é, por um lado, menos vertical que aquele dos tribunais ad hoc, mas que, por outro lado, vai mais além de uma cooperação simplesmente horizontal ${ }^{28}$. Esse resultado é conseqüência do fato de que o regime de cooperação do TPI está baseado em um tratado de direito internacional que deve reconciliar os antes mencionados conflitos de interesses, e que não pode ser imposto pelo Conselho de Segurança da ONU. Em essência, o dever de cooperar previsto no artigo 86 do Estatuto do TPI, antes de mais nada, pressupõe a ratificação por parte dos Estados desse tratado ou pelo menos a conclusão de um acordo ad hoc conforme o artigo 87(5) do Estatuto do $\mathrm{TPI}^{29}$. Portanto, tem-se que fazer uma distinção entre a obrigação geral de cooperar dos Estados-membros e a obrigação limitada dos Estados que não são parte do tratado. Ademais, a obrigação de cooperar está vinculada às investigações do Procurador ("Anklagebehörde"), pois, constitui uma condição para a autorização de uma investigação pela Câmara de Julgamento Preliminar, segundo o artigo 15(4), ou a decisão de abrir a investigação, segundo o artigo 53(1) do Estatuto do TP ${ }^{30}$.

Existem também alguns argumentos para negar a cooperação. Por exemplo, a entrega de uma pessoa pode ser adiada se ainda não houve decisão de admissão pelo TPI (artigo 17 (1) (c), artigo 20 (3) do Estatuto do TPI) ou se um conflito sobre a admissibilidade conforme os artigos 18 e 19 está pendente (artigo 95 do Estatuto do TPI) ${ }^{31}$. Também, o regime de descumprimento com respeito à obrigação de cooperar é diferente quanto aos

\footnotetext{
${ }^{27}$ Para mais detalhes sobre as negociações P. MOCHOCHOKO, em: R. S. LEE (ed.), The International Criminal Court (1999), pp. 305 e ss.; C. KREB, European Journal of Crime, Criminal Law and Criminal Justice 1998, pp. 449 e ss.; C. KREB et al. (supra nota 17), parte 9, nm. 4.

${ }^{28}$ Ver C. KREß (supra nota 21), comentário preliminary III 26, nm. 206 para exemplos de elementos horizontais e verticais; B. SWART (supra nota 17), pp. 1594 e ss.; C. KREB et al. (supra nota 17), parte 9, nm. 5; Kai AMBOS (supra nota 21), pp. 413 e ss. J. MEIBNERr (supra nota 20), pp. 275 e ss.; G. SLUITER 2002 (supra nota 20), pp. 82 e ss.; P. CAEIRO, en: V. MOREIRA et al., O Tribunal Penal Internacional e a ordem jurídica portuguesa (2004), pp. 69157 at p. 70.

${ }^{29}$ G. SLUITER 2002 (supra nota 20), pp. 68 e ss.; A. CIAMPI (supra nota 16), pp. 1615 e ss.; C. KREB et al. (supra nota 17), artigo 87, nm. 18 e ss.; G. PALMISIANO, en: F. LATTANZI y W. A. SCHABAS (eds.), Essays on the Rome Statute (1999), pp. 402 e ss.

${ }^{30}$ TPI-Gabinete do Procurador, 2003, 10.

${ }^{31}$ Para mais exemplos e referências ver K. AMBOS (supra nota 8), § 8, nm. 65, 79.
}

Revista Brasileira de Direito Internacional, Curitiba, v.1, n.1, jan./jun.2005 
Estados Partes e aos Estados não-partes. No caso de descumprimento do dever de cooperar, o TPI pode fazer uma declaração a respeito e referir o problema à Assembléia dos Estados-parte ou, quando o Conselho de Segurança tiver enviado o assunto ao Tribunal, ao próprio Conselho de Segurança (artigo 87 (7) e artigo 112 (2) (f) $)^{32}$. No caso dos Estados nãomembros, o TPI pode remitir o problema à Assembléia dos Estados ou, se for necessário, ao Conselho de Segurança, mesmo sem a declaração mencionada acima.

\subsection{A COOPERAÇÃO NA PRÁTICA}

Ao passar desse marco teórico às questões práticas, a primeira questão que o Procurador deve saber é com quem cooperar. Essa pergunta, deveria, junto com outras, ser resolvida com as leis nacionais de cooperação dos Estados Partes, mas até o momento somente poucos deles implementaram essa legislação e, basicamente, apenas aqueles onde a prática de crimes internacionais não é muito provável (os Estados-membros da União Européia e o Canadá $)^{33}$. Assim, o Procurador, na prática, será confrontado com a situação de querer investigar em um Estado determinado, mas este não conta com um marco jurídico apropriado sobre a cooperação com o TPI. Esse é o caso em todos os Estados africanos onde existem atualmente investigações em curso e, por esta razão, o Procurador deve buscar acordos específicos e em separado com eles para definir as regras de cooperação.

\footnotetext{
${ }^{32}$ Cf. C. Kreß (supra nota 17), artigo 86, nm. 1 e ss.; A. Ciampi (supra nota 16), pp. 1608 e ss.; C. Kreß et al. (supra nota 17), artigo 87, nm. 32 e ss.; G. Sluiter 2002 (supra nota 20), pp. 67 e ss. Concernente à posição especial do Conselho de Segurança ver G. Palmisano (supra nota 29), pp. 416 e ss.; P. Gargiulo, en: F. Lattanzi y W. A. Schabas (eds.) (supra nota 29), pp. 100 e ss.

${ }^{33}$ Cf. Implementação da Amnistía Internacional http://web.amnesty.org/pages/icc-implementation-eng. De acordo com o informe "International Criminal Court: The failure of States to enact effective implementing legislation", Al índice: IOR 40/019/2004, $1^{\circ}$ de setembro de 2004 até 23 de agosto de 2004 somente 36 dos 94 Estados-parte promulgaram legislação para a implementação de qualquer de suas obrigações em face do Estatuto de Roma. Segundo a revista ICC Monitor, no. 32, Maio de 2006, p. 5, até janeiro de 2006, 40 dos 100 Estados-parte adotaram legislação referente ao Estatuto de Roma. 30 Estados adotaram legislação material e 32 legislação de cooperação; 37 Estados têm projetos de legislação material e 27 de cooperação; 33 não têm nenhum tipo de legislação material e 41 nenhuma de cooperação.
}

Revista Brasileira de Direito Internacional, Curitiba, v.1, n.1, jan./jun.2005 
Além disso, vários problemas práticos surgem, independentemente da existência de uma legislação de cooperação. Um bom exemplo se refere à questão do transporte e do movimento dentro de certo país. Uma equipe de investigadores pode, mais ou menos facilmente, chegar da Haia à capital de um país "sob investigação", mas já o transporte interno deve ser organizado com a ajuda de autoridades locais, por exemplo, a fim de conseguir a autorização necessária para comprar ou alugar um automóvel e realizar uma viagem por todo o país. Enquanto os problemas burocráticos podem ser superados com paciência e insistência, a carência de segurança para os investigadores pode obstaculizar totalmente uma investigação. O governo sudanês, por exemplo, expressou várias vezes sua falta de vontade geral de cooperar com o TPI na investigação de Darfur ${ }^{34}$ e quando a primeira missão do Tribunal deveria chegar no início de março, o Ministro da Justiça advertiu que não chegariam a Darfur ${ }^{35}$. Na etapa inicial da investigação, o governo sudanês inclusive ameaçou o Procurador: "se você enviar uma equipe de investigação, deve ir preparando uma segunda, porque a primeira não sobreviverá." Assim, está claro que qualquer investigação dessa classe requer ajuda militar pelas forças locais ou multinacionais da ONU para superar os problemas logísticos e de segurança. Ao final do dia, como se sabe da experiência na antiga lugoslávia, para realizar a detenção de um suspeito se requer uma força policial ou militar.

Diante desse panorama, é compreensível que o Procurador hesite em fazer uso de seu poder motu proprio contemplado pelos artigos 13(c) e 15 do Estatuto do TPI. Enquanto o envio de um Estado sob os artigos 13(a) e 14 do Estatuto implica na vontade de cooperar desse Estado (de outra maneira não seria sensato por parte do Estado pedir uma investigação ao Procurador) e o envio por parte do Conselho de Segurança sob o artigo 13(b) tem o suporte da autoridade do Conselho de Segurança e seus poderes sob o Capítulo VII da Carta das Nações Unidas ${ }^{36}$, no caso de uma investigação motu proprio o

\footnotetext{
${ }^{34}$ Ver, por exemplo: http://www.alertnet.org/thenews/newsdesk/MCD344183.htm.

35 Tribuna do Sudão "ICC delegation to visit Sudan's Darfur", 27 de fevereiro de 2006, http://www.sudantribune.com/article.php3?id_article=14271.

${ }^{36} \mathrm{Na}$ resolução SC-Res. 1593 de 2005, cf. nota 4, o Conselho de Segurança limitou os poderes do TPI: "6. Decides that nationals, current or former officials or personnel from a contributing
}

Revista Brasileira de Direito Internacional, Curitiba, v.1, n.1, jan./jun.2005 
Procurador, basicamente, está atuando por sua conta e apenas pode confiar no apoio dos que submetem a informação sob o significado do artigo 15(2), vale dizer, as vítimas ou ONGs. A partir da perspectiva do Estado em questão, uma investigação motu proprio seguramente será considerada como uma invasão em seus assuntos internos, quase como um ato de inimizade, e o Estado fará todo o possível para frustrar dita investigação. Esse panorama é também aplicável para a Colômbia, onde, por um lado, como se mencionou anteriormente, crimes dentro da jurisdição do TPI foram e estão sendo cometidos, porém, por outro lado, o governo faz tudo para evitar uma investigação formal do TPI. Não obstante, por todas essas considerações importantes da "Realpolitik", não se deve perder de vista o objetivo real do TPI: "por fim à impunidade para os perpetradores" dos mais importantes crimes internacionais (preâmbulo do Estatuto do TPI, parágrafo 5). Esse último objetivo, certamente, não se pode adiar para sempre por razões de Realpolitik. Isso nos conduz à questão de como o TPI pode -- apesar da resistência de certos Estados ou governos -- assegurar uma investigação apropriada.

State outside Sudan which is not a party to the Rome Statute of the International Criminal Court shall be subject to the exclusive jurisdiction of that contributing State for all alleged acts or omissions arising out of or related to operations in Sudan established or authorized by the Council or the African Union, unless such exclusive jurisdiction has been expressly waived by that contributing State." [6." Decide que nacionais, atuais ou antigos oficiais, ou pessoal de um país colaborador fora do Sudão que não seja parte do Estatuto de Roma do Tribunal Penal Internacional, serão sujeitos à competência exclusiva desse país colaborador para todos os atos e omissões que surjam ou se relacionem com operações no Sudão estabelecidas ou autorizadas pelo Conselho ou a União Africana, a menos que essa competência exclusiva tenha sido expressamente renunciada pelo Estado colaborador"].

Revista Brasileira de Direito Internacional, Curitiba, v.1, n.1, jan./jun.2005 


\section{POSSÍVEIS PRESSÕES SOBRE ESTADOS QUE NÃO QUEREM COOPERAR}

Nesse ponto, a questão mais importante é qual pressão poderia ser exercida aos Estados que não querem cooperar com o TPI. Antes de tudo, como declarado anteriormente, a obrigação de cooperar somente existe com respeito aos Estados Partes (artigo 86 do Estatuto do TPI). Os Estados que não fazem parte podem, na ausência de um acordo ad hoc (artigo 87 (5)), somente serem obrigados a cooperar através de uma resolução do Conselho de Segurança devido ao seu caráter obrigatório sobre todos os membros da ONU, conforme o artigo 25 da Carta das Nações Unidas. Em qualquer caso, enquanto aos Estados obrigados a cooperar, a única via legal de alcançar seu cumprimento é referir uma denúncia de não-cooperação - depois de uma declaração para este efeito, pelo Tribunal - à Assembléia dos Estados Partes (artigo 87 (5)(b), (7) e artigo 112 (2)(f)). É assim que numa referência do Conselho de Segurança, por exemplo no caso de Darfur/Sudão, o assunto também pode, como se mencionou acima (III.1.), ser indicado ao Conselho de Segurança (artigo 87 (5)(b),(7)).

Esse é, certamente, o melhor regime possível de cumprimento dentro do marco do tratado em que se baseia o TPI, embora não deixe de compartilhar os problemas de qualquer regime de cumprimento em direito internacional. Enquanto que, na teoria, existem diferentes mecanismos de execução, por exemplo, o uso de estímulos econômicos de ajuda e as sanções econômicas diplomáticas, congelamento dos ativistas criminais de guerra, oferecimento de recompensas individuais e, último mas não menos importante, o uso da força militar para efetuar apreensão ${ }^{37}$; na prática todos estes mecanismos resultam altamente polêmicos.

Ao lado disso, o fato de estarmos nos ocupando da não-cooperação em investigações de crimes cometidos em território ou pelas forças de certos países pertencentes ao "terceiro mundo", tornam as coisas ainda mais complicadas. Realmente seria plausível, por exemplo, que a União Européia

${ }^{37}$ Cf. A. WARTANIAN, Georgetown Journal of International Law 2005, pp. 1302 e ss.; M. P. SCHARF, Depaul Law Review 2000, pp. 938 e ss.

Revista Brasileira de Direito Internacional, Curitiba, v.1, n.1, jan./jun.2005 
exerça pressão econômica sobre os Estados Africanos sem vontade de cooperar, em uma época de redução de dívida externa e de luta contra a pobreza global? Se a União Européia reduzisse a ajuda para o desenvolvimento porque um Estado não coopera com o TPI entraria em conflito com seus principais objetivos na política do desenvolvimento. De fato, pode-se até induzir a atual administração dos Estados Unidos da América à cômoda posição de argumentar contra o TPI como uma Corte antidesenvolvimento, com a UE unicamente suportando (financeiramente) Estados cooperativos e os Estados Unidos da América, em oposição, beneficiando-se da não-cooperação. Essas considerações, por certo superficiais, demonstram que, por um lado, a pressão econômica pode ser contrária, e , por outro, que a denúncia de nãocooperação requer soluções mais sofisticadas, as quais, certamente, não são fáceis de encontrar.

Revista Brasileira de Direito Internacional, Curitiba, v.1, n.1, jan./jun.2005 


\section{A COMPLEMENTARIDADE E OS SISTEMAS DE JUSTIÇA PENAL}

De acordo com o princípio da complementaridade, o TPI "complementa" os sistemas de justiça penal domésticos em relação à perseguição do genocídio, crimes contra a humanidade e crimes de guerra. De fato, o TPI se mantém à margem se o Estado "que possui jurisdição" investiga os crimes seriamente e pune os responsáveis. Esse princípio está contido no parágrafo 10 do preâmbulo e várias provisões do Estado, o mais importante dos quais é o artigo 17 (veja-se também os artigos 1, 18 e 19). A razão fundamental do princípio é que, por um lado, constitui tarefa principal dos Estados ajuizar delitos internacionais, especialmente se foram cometidos em seu território; por outro lado, deve-se reconhecer que o Tribunal Penal Internacional nunca poderá, em termos de sua capacidade processual, substituir os Estados nessa tarefa. O papel do TPI, assim, em princípio, se limita a monitorar ou supervisionar sistemas nacionais e eventualmente apoiálos em seus ajuizamentos nacionais. Isso está claramente expresso na iniciativa de alguns Estados para estabelecer a chamada "Capacidade de resposta rápida da Justiça" (Justice Rapid Response Capacity) do TPI, para ajudar aos Estados dispostos, mas incapazes, de conduzir seus próprios processos $^{38}$.

Essa é, geralmente, uma aproximação convincente, não somente por razões da "Realpolitik" (o estado territorial está "mais próximo" dos acontecimentos, da evidência, etc.), mas também devido ao fato de que, em última análise, o objetivo final de perseguição dos delitos internacionais é não somente a prevenção da impunidade, nos casos concretos - alguém poderia chamar isso de aspecto dos direitos humanos - mas também a melhoria dos sistemas da justiça penal em sua totalidade (o aspecto da reforma judicial). Em

\footnotetext{
${ }^{38}$ Ver "Justice Rapid Response Feasibility Study", outubro de 2005, produzido pelo pedido e apoio dos governos da Finlândia, Alemanha, Liechtenstein, Suécia, Suíça e Reino Unido; ver também K. AMBOS (supra nota 8), $\S 8, \mathrm{mn}$. 16. Na quinta reunião sobre o tema se enfatizou 0 valor de "Justice Rapid Reponse" como mecanismo de cooperação internacional e se introduziu as seguintes medidas práticas: "1.Focal Points, 2. Rosters, 3. Training, 4. Standard operating procedures, 5. Cooperating among among interested parties, 6. Ultimate coordination of JRR, 7. Promoting participation" (cf. Chair's Conclusions of the Venice Conference on Justice Rapid Response, 15-17 Junho 2006).
}

Revista Brasileira de Direito Internacional, Curitiba, v.1, n.1, jan./jun.2005 
outras palavras, a questão do ajuizamento de sérias violações aos direitos humanos pelo próprio Estado está ligada à questão de reforma judicial, ao estado de direito, a um melhor aceso à justiça etc. A última meta é alcançar um sistema governado por regras de um estado de direito e com um acesso a justiça para todos os cidadãos, independente de seu estado social. Claramente, essa é a perspectiva mais ampla de governabilidade e de reforma judicial que vai além do aspecto dos direitos humanos. Dessa perspectiva, os procedimentos dos direitos humanos deveriam ser uma via para melhorar os sistemas judiciais: o tema dos direitos humanos não pode se limitar somente aos delitos internacionais, pois abrangem também outros casos "normais" em todas as áreas do sistema legislativo e judicial.

Revista Brasileira de Direito Internacional, Curitiba, v.1, n.1, jan./jun.2005 


\section{PROBLEMAS COM A JURISDIÇÃO UNIVERSAL E A SOLUÇÃO} ALEMÃ

A já mencionada fórmula de "quem tem jurisdição sobre ele" do artigo 17 do Estatuto é muito ampla. De fato, tomando seriamente o sentido literal do artigo, qualquer forma de jurisdição incluindo todas as formas de jurisdição extraterritorial, especialmente jurisdição universal, estão abrangidas. Assim, um Estado que não possui nenhum vínculo real com o crime ou suspeito em questão poderia demandar jurisdição com base no princípio de jurisdição universal, em se tratando de um crime internacional sério (core crime) e, portanto, estaria abrangido por este princípio ${ }^{39}$; por conseqüência, esse Estado teria primazia sobre o TPI com respeito ao referido crime. Concretamente, no caso de Pinochet, onde vários Estados, inter alia Espanha e Alemanha, invocaram o princípio da jurisdição universal para acionar Pinochet em seus tribunais nacionais, estes Estados teriam primazia sobre o $\mathrm{TPI}^{40}$. Essa é, de fato, a interpretação feita pelo Gabinete do Procurador e pela Comissão Internacional de Investigação em Darfur ${ }^{41}$.

O último caso mostra claramente que tão ampla interpretação do artigo 17 do Estatuto do TPI pode gerar resultados opostos. Primeiro, aumentaria, em vez de diminuir, as tensões entre Estados que demandam a jurisdição universal em casos como o de Pinochet e aqueles que consideram o exercício da jurisdição extraterritorial, em tais casos, como uma intervenção em assuntos internos. Em segundo lugar, deixaria o TPI virtualmente sem casos, dado que todos os crimes da competência material do TPI são objeto, per defectionem, de jurisdição universal, e poderiam, portanto, ser ajuizados por Estados em vez do TPI. Por essas razões, o ponto de vista oficial alemão é mais restritivo em

\footnotetext{
${ }^{39}$ Ver sobre a razão de ser e o âmbito de aplicação do princípio de jurisdição universal K. AMBOS (supra nota 8), § $3 \mathrm{mn} .93$ e ss.

40 Veja F. de GURMENDI, Chefe do Gabinete de Ministros e Conselheiro Especial do Procurador, entrevista com o autor, Haia, 27 de setembro de 2005.

${ }^{41}$ Relatório da Comissão Internacional de Investigação sobre Darfur para a Secretaria Geral das Nações Unidas, conforme a Resolução 1564 de 18 de Setembro de 2004 do Conselho de Segurança, 2005, parágrafo 616: "The ICC should defer to national courts other than those of Sudan which genuinely undertake proceedings on the basis of universal jurisdiction"; [ o TPI deveria conceder uma prorrogação às cortes nacionais, fora as do Sudão, que genuinamente empreendem processos baseados em jurisdição universal"]; ver também M. DELMAS-MARTY, JICJ 2006, p. 6.
}

Revista Brasileira de Direito Internacional, Curitiba, v.1, n.1, jan./jun.2005 
atenção ao artigo 17 do Estatuto do TPI, interpretando "quem tem jurisdição sobre ele" em referência às formas tradicionais de competência, vale dizer, competência baseada nos princípios de territorialidade (ativa e passiva), de personalidade e ao princípio protetor (real $)^{42}$. A lei alemã implementa este ponto de vista com uma combinação peculiar substantivo-processual de normas. A lei substantiva, isto é, o Código Alemão de Direito Penal Internacional (Völkerstrafgesetzbuch, de agora adiante "VStGB") ${ }^{43}$ prevê no $§ 1$ um amplo princípio de jurisdição universal, indicando que: "Esta lei se aplicará a todas as ofensas penais contra o direito internacional designadas segundo esta lei, como ofensas penais sérias ${ }^{44}$, inclusive quando a ofensa foi cometida no estrangeiro e não tenha nenhuma relação com a Alemanha."

Tal norma é a solução mais ampla possível e reflete a visão alemã expressada em Roma: que para os crimes mais graves como genocídio, crimes contra a humanidade e crimes de guerra, o princípio de jurisdição universal deve aplicar-se. No entanto, por razões práticas ou, outra vez, "Realpolitik" (inter alia, pressão do Gabinete do Procurador Geral Federal Generalbundensanwaltschaft), uma restrição a este amplo princípio substantivo tinha que ser encontrado e, portanto, § $153 f$ do Código de Procedimento Penal Alemão ("Strafprozessordnung", doravante "StPO") foi criado. Essa norma ${ }^{45}$ completa assinala:

“(1) nos casos referidos segundo o $\S 153 c$ subseção (1), números 1 e 2 [crimes extraterritoriais], o Gabinete Público do Procurador pode dispensar o ajuizamento de um delito punível conforme os $\S \S 6$ a 14 do Código de Crimes contra o Direito Internacional, se o acusado não está presente na Alemanha e não se espera tal presença. Se nos casos referidos segundo o $§ 153 c$ subseção (1), número 1, 0 acusado é um alemão, isto se aplicará somente quando a ofensa esteja sendo

\footnotetext{
${ }^{42}$ Sobre este princípio ver K. AMBOS (supra nota 8), § $3 \mathrm{mn} .1$ e ss.

${ }^{43}$ Para uma tradução em vários idiomas (inglês, árabe, chinês, espanhol, francês, grego, russo e português) ver http://www.jura.uni-goettingen.de/k.ambos/Forschung/laufende_Projekte_Translation.html.

${ }^{44} \mathrm{Na}$ lei Alemã, o termo "ofensas penais sérias" (Verbrechen) é usado para indicar ofensas penais (Straftaten) que são puníveis com não menos de um ano de prisão. Circunstâncias atenuantes (e agravantes), como são reguladas, por exemplo na seção 8 subseção (5), devem ser desconsideradas neste aspecto (seção 12 do Código Penal Alemão). Como resultado, todas as ofensas criminais no VStGB são "ofensas penais sérias" com somente a exceção das ofensas penais das seções 13 e 14.

${ }^{45}$ Para uma análise ver K. AMBOS (supra nota 8), § $3 \mathrm{mn}$. 100; mais detalhada, id., em Münchner Kommentar StGB und Nebenstrafrecht, vol. VI, para 1 VStGB, mn. 24 e ss. (a ser publicado em 2007).
}

Revista Brasileira de Direito Internacional, Curitiba, v.1, n.1, jan./jun.2005 
processada perante um tribunal internacional ou por um Estado cujo território a ofensa foi cometida ou cujo nacional foi prejudicado com a ofensa.

(2) nos casos referidos segundo o $\S 153$ c subseção (1), números 1 e 2, o Gabinete Público do Procurador pode, em particular, dispensar o processamento de uma ofensa punível conforme os $\S \S 6$ a 14 do Código de Crimes contra o Direito Internacional, se:

1. não há suspeita de que um alemão cometeu tal delito,

2. tal delito não foi cometido contra um alemão,

3. ninguém suspeito pelo que se refere tal delito esteja residindo na Alemanha e tal residência não é prevista e

4. a ofensa está sendo processada perante uma Corte Internacional ou por um Estado cujo território se cometeu tal delito, cujo nacional é suspeito de haver cometido o delito ou cujo nacional foi prejudicado pelo delito.

O mesmo de aplicará se um estrangeiro acusado de um delito cometido no estrangeiro esteja residindo na Alemanha mas os requisitos conforme a primeira regra, números 2 e 4, tem sido satisfeitos e a transferência a uma Corte Internacional ou a extradição ao Estado que está levando fim o processamento é permitida.

(3) Se nos casos referidos segundo a subseção (1) ou (2) cargos públicos se tem preferido, o Gabinete Público do procurador pode retirar os cargos em qualquer etapa do procedimento e terminar o procedimento."

Essa norma prevê uma exceção ao princípio da legalidade processual (dever de perseguição) que governa, em princípio, o procedimento penal alemão. Enquanto que a regra da legalidade processual se enfraquece seriamente, inclusive alguns podem ser indeterminadas; por várias exceções (§§ 153, 153a, 153b, 153c, 153d, 153e, 154, 154 $\mathrm{a}$ StPO) deixando ao Procurador uma ampla discricionariedade para encerrar ou suspender uma investigação em curso, a diferença principal entre essas exceções e o novo § 153 StPO é que as primeiras (as exceções tradicionais), em termos gerais, referem-se a delitos menos importantes mas não aos crimes internacionais mais graves. Somente o $\S 153 \mathrm{c}$ StPO, mencionado no parágrafo 1 do $\S 153 \mathrm{f}$, refere-se a qualquer crime "cometido no estrangeiro", portanto, cobrindo também, na teoria, os crimes internacionais. Seja como for, o problema conceitual do $\S 153 f$ é a dificuldade em justificar uma exceção ao princípio da legalidade processual no caso de crimes internacionais cujo processamento inclusive deriva de um tratado internacional e de direito consuetudinário ${ }^{46}$. Além disso, segundo a visão dominante, não há remédio contra a decisão negativa do Procurador abster-se de uma investigação ou para parar uma investigação. Esse ponto de vista tem sido confirmado pelo Tribunal de Apelação de Sttugart

\footnotetext{
${ }^{46}$ Ver K. AMBOS, Archiv des Völkerrechts 1999, pp. 318 e ss.; id., Impunidade e Direito Penal Internacional, $2^{\mathrm{a}}$ ed. (1999), pp. 66 e ss.
}

Revista Brasileira de Direito Internacional, Curitiba, v.1, n.1, jan./jun.2005 
(Oberlandesgericht) $^{47}$ no caso de Rumsfeld et al./Abu Ghraib analisado detalhadamente em outro lugar ${ }^{48}$. Essa visão tão restritiva é difícil de se manter dada a ampla discricionariedade legal ou normativa do Promotor ao tomar uma decisão segundo o $\S 153$ StPO. Deve, portanto, ser possível submeter essa decisão a uma revisão judicial ${ }^{49}$.

\footnotetext{
${ }^{47}$ Decisão de 13 de setembro de 2005, publicada em Neue Zeitschrift für Strafrecht 2006, p. 117. Para um comentário crítico, K. AMBOS, Neue Zeitschrift für Strafrecht 26 (2006), 434 ss.

48 Ver W. KALECK e F. JESSBERGER em Kaleck/Ratner/Singelnstein/Weiss (eds.), International prosecution of human rights crimes, Berlin et al. 2006, prüfen.

49 Para uma discussão mais detalhada ver Ambos (nota supra 47); id. (nota supra 45), § 1 VStGB, mn. 31.
}

Revista Brasileira de Direito Internacional, Curitiba, v.1, n.1, jan./jun.2005 


\section{CONCLUSÃO}

Este artigo buscou demonstrar que o ajuizamento de crimes internacionais ao nível supranacional e nacional encontra várias limitações e problemas que de uma forma ou de outra podem remontar novamente ao tema comum da Realpolitik. O TPI segue sendo uma instituição em desenvolvimento e não pode resolver, de um dia para o outro, velhos problemas de séculos de impunidade por violações graves aos direitos humanos. Grandes expectativas podem ser contrárias e, em última instância, provocar o fracasso do TPI. Assim, cautela e uma dose de "Realpolitik" de alguns amigos nãogovernamentais do TPI são requeridas. Neste momento, o TPI, pelo menos o Gabinete do Procurador, funciona com total capacidade em suas três investigações e é difícil observar como estaria se possuísse mais casos. ${ }^{50}$ Apesar de, a partir de uma perspectiva puramente legal e segundo uma obrigação, o Procurador poder processar motu proprio (princípio da legalidade processual) casos com base no artigo 13 (c) e 15 do Estatuto, a situação real aparentemente não permite mais casos para serem investigados e, em qualquer hipótese, uma investigação motu proprio enfrentaria mais problemas que investigações baseadas em referências do Conselho de Segurança da ONU ou de um Estado. Novamente, ainda que este seja um problema de Realpolitik e, portanto, de difícil aceitação para um jurista, não há mais alternativa além de considerar as limitações reais, especialmente se tratar-se de uma instituição que ainda está em fase de construção e consolidação.

\footnotetext{
50 Assim, o vice-procurador Serge Brammertz assinalou que todos os investigadores estão trabalhando em equipes distribuídas por todo o mundo e que ele não pode se encarregar de um deles para levar a fim conferências em universidades ou outros círculos interessados (entrevista com o autor, Haia, 26 de setembro de 2005).
}

Revista Brasileira de Direito Internacional, Curitiba, v.1, n.1, jan./jun.2005 